\title{
SPAWNING HABITS OF THE SPINY LOBSTER (PANULIRUS ARGUS), WITH NOTES ON ARTIFICIAL HATCHING
}

\author{
By D. R. Crawford \\ Scientific Assistant, $U$. S. Bureau of Fisheries \\ Washington, D.C.
}

Since the spawning act among the larger crustaceans has been observed so infrequently, any additional information is of interest and value. Herrick records no direct observation of the spawning act of Homarus americanus. Scott records one observation on the spawning of the European lobster, Homarus gammarus.* Although the available literature has been searched, no record of the direct observation of the spawning of the blue crab or spiny lobster has been found.

The difficulties surrounding observations of this sort are numerous and often insurmountable, and the one who has an opportunity to observe the spawning act is indeed fortunate. It seems that crustaceans rarely spawn in captivity unless they are captured just prior to the time when spawning would have occurred under natural conditions. Close confinement often causes abnormal conditions to which the crustacean does not become adapted. It is pointed out that the spiny lobster, which was observed in this case, was confined but one day before the act of spawning took place.

A brief review of the external features of the anatomy which are peculiar to the female will be helpful in understanding what is to follow.

The fifth claw of the female, which differs from that of the male, is considerably modified. At the articulation of the dactyl with the propodus, there is a small chela which is composed of spur-like extensions of the propodus and dactyl. The inner surfaces of this chela are concave and the rims are com-

\footnotetext{
- Report for 1902 on the Lancashire and Sea Fisheries Laboratory at University College, Liverpool, and the Sea Fishery Hatchery at Piel, pp. 20-27. Liverpool, 1902.
} 
posed of dense, hard chiton. There are silky tufts of short setæ on the dactyl. The pleopods of the female differ from those of the male in the development of the endopodites of the last three pairs, the first pair of endopodites resembling the exopodites. The last three pairs of endopodites are bifurcated and fringed with long, hair-like setæ protruding in tufts from the margins which are reenforced by thickened scutes at these places. All of these hairs are not the same in character, for it is found that some of them are plumose and shorter than the others which are simply rod-shaped. These simple hairs carry the eggs when they are laid.

The spermatozoa are carried in a vesicle which is deposited on the sterna of the female between the last three pairs of legs. This vesicle has no internal connections with the ovaries and fertilization of the eggs necessarily takes place after they leave the oviducts. The oviducts open on the coxæ of the third pair of legs which is anterior to the great bulk of the vesicle. The eggs, therefore, must pass over the vesicle before they reach their place of attachment on the pleopods.

On May 5, 1919, at the U. S. Bureau of Fisheries Biological Station at Key West, Fla., a female spiny lobster which had been captured the day before, was observed resting in one corner of the enclosure with the pleon slightly flexed and the margin of the telson resting lightly on the bottom. There was nothing unusual to suggest that spawning was about to occur.

Presently, the fifth pair of legs was carried slowly foreward and the dactyls reached underneath the body in the region of the seminal vesicle. The poking action continued for about five minutes when the spiny lobster was removed from the water. It was observed that the exterior of the seminal vesicle was being scraped off. After replacing the animal in the water, this action continued for half an hour, after which time it was observed that the posterior third of the vesicle was scraped off, showing a pinkish interior.

Forty-five minutes after the observation started, the movements of the fifth pair of legs were quickened and they passed 
backward to the pleopods. It is not supposed that the eggs were being carried backward by the chelæ of the fifth pair of legs. A number of estimates showed that a female spiny lobster carries about 700,000 eggs. This large number, together with the time in which they were deposited and the way in which they were attached to the hairs of the pleopods, precludes the possibility that they could have been deposited with the aid of the chelæ. These appendages are used to remove the surface of the vesicle and, later on, to manipulate the eggs after they are laid. Whether or not small pieces of the vesicle containing spermatozoa were conveyed to the pleopods is not known, but the action of the fifth pair of legs suggests this possibility.

The pleopods during this time beat slowly and rhythmicly from side to side. That eggs were being extruded was suggested by the continuous attacks of small fishes which darted in toward the pleon. It was very desirable for various reasons to learn, if possible, how long the eggs were carried, and so the female was not disturbed. It, however, was noted that the eggs were all laid six hours later when the spiny lobster was removed for observation. Whether the time for egg laying is any shorter than six hours was not learned from this, or subsequent observations of several other females which spawned in captivity.

The eggs may be extruded with considerable force since the mature ovaries are very large in proportion to the other viscera and they must be under considerable pressure. The fanning motion of the pleopods could have carried the eggs backward against the endopodites. The fact that the eggs are fastened to no other parts of the body than the simple hairs of the last three pairs of endopodites suggests that the cementing substance, whatever it may be, is secreted from the endopodites. Glands for this secretion, however, have yet to be demonstrated.

Unfortunately, this spiny lobster died, but observations of three other females which spawned in captivity showed that 
in three cases at least, the incubation period of the eggs is eighteen days. Probably three weeks is more exact for natural conditions, since the water at this time was very warm.

It was observed that the remains of the seminal vesicle are picked off a few days after the eggs have hatched. It is thus possible to estimate within close bounds the spawning time of any number of females which may be caught. If conditions are favorable, the females molt ten days or two weeks after the vesicle is picked off. Mating takes place, as observed in one instance, shortly after molting, while the shell is still soft.

The eggs are bright coral red when they are first laid, but they change to brown and finally clear, light gray as the developing embryo absorbs the yolk material. The approximate age of the eggs can be judged by observing their color. The newly laid eggs are slightly oval, measuring about 0.45 $\mathrm{mm}$. by $0.5 \mathrm{~mm}$. They increase slightly in size and become spherical as the embryo develops.

Experiments in artificial hatching of the young were carried on at the Biological Station at Key West in 1917 and 1918. The first apparatus consisted of boxes made of wooden frames covered with cloth in which a female bearing eggs was placed. The eggs were allowed to hatch and the female was removed when the larvæ were observed at the surface. This apparatus proved unsuccessful in rearing the larvæ. In 1918, more extensive experiments were carried on. A small battery of McDonald hatching jars was set up and supplied with running salt water. A wooden trough was provided to catch the overflow from the jars and a device was developed to keep the water circulating upward from the bottom.

The eggs were found to be rather difficult to strip since they adhered to the pleopods quite securely. At first, only those eggs which were known to be about to hatch were placed in the jars. It was not difficult to select females bearing such eggs, for it was observed that when the eggs are in such an advanced state of development, the females are less active than those bearing newly laid eggs. The females do 
not take food readily while bearing eggs, and the reduced activity may be caused by starvation. The eggs which are about to hatch are clear gray and the embryo can be seen plainly through the outer membranes. They are semi-buoyant and the flow of water through the jars must be gauged carefully.

The first larvæ to emerge in the jars hatched abnormally because of evident injury to the eggs while stripping them. These larvæ did not succeed in casting off the embryonic sheath which covers all parts of the exterior and in which the exopodites of the natatory appendages are folded down closely to the endopodites. These larvæ quickly died. The first normal larvæ emerged during the night. It was observed that just before hatching, the eggs became buoyant and as they floated upward, the larvæ ruptured the outer shell and emerged much doubled up like flecks of cotton waste. In a few seconds, the larvæ straightened out and began actively swimming about. The larvæ have two movements; the first is a rotary movement which causes the larva to proceed by a series of summersaults; the second movement is spiral, the larva rotating on its longitudinal axis as it moves forward.

The first stage larva, or phyllosome, is quite small, the body, excluding the antennæ and legs, measuring $0.9 \mathrm{~mm}$. in length and about $0.7 \mathrm{~mm}$. in width. It is transparent except for the dense black eyes and yellowish liver mass. The legs which are developed in this stage correspond to the third maxillipeds and the last three pairs of legs in the adult. The first two pairs of legs posterior to the maxillipeds have well-developed exopodites with which the larva swims. The exopodites on the last pair of legs are reduced to short spurs. The legs are very long in proportion to the body and they are provided with numerous setæ and spines. The first two pairs of dactyls are very long and curved slightly while the last pair of dactyls is short and hook shaped. It was observed that these long legs became entangled when the larva were 
crowded and that it was impossible to separate the larvæ. Consequently, they sank to the bottom in tangled mats and soon died.

Experiments with newly laid eggs were unsuccessful because they adhered in compact masses which could not be separated. None of them developed to the stage in which the eye of the embryo can be seen. Stripping evidently injured most of them before they were placed in the jars. Under natural conditions, the eggs on the pleopods of the female are manipulated with far greater care.

Although none of the larvæ was reared beyond the first stage, the experiment was important because it showed that fluctuations in the temperature of the water are detrimental to hatching and that the optimum temperature is not far from $\mathbf{7 5}$ degrees F. This temperature was observed at the hatchery only at night during a rising tide when the water was flowing in from the open sea. This strongly suggested that the temperature of the water in which the eggs naturally hatch is about 70 degrees, since the incoming water would rise in temperature as it mixed with the much warmer shallow water over the flats, thus accounting for the higher temperature observed at the hatchery.

This fact is rather important for it tends to disprove the common belief that hatching naturally takes place in shallow water. Extensive observations over a period of two years showed that the fluctuations in temperature of the shallow water are too great and too sudden and that the maximum temperature frequently rises beyond that which was observed to be the thermal death-point of the larvæ, viz., 98 degrees F. Although occasional females may. stay in shallow water while the eggs hatch, it does not seem likely that any great number of the larvæ survive. The fact that large numbers of spawn bearing females are caught in shallow water does not prove that they remain there while the eggs hatch, for it is well known that large numbers of spiny lobsters migrate shore- 
ward during the night and on stormy days when the inshore water is cool for the purpose of feeding. No females with well-developed eggs were ever taken at the station in traps set in shallow water, and among many hundreds brought into the market at Key West none was observed with brown or light gray eggs unless the fisherman had set his traps in deeper water than usual. That the eggs hatch normally while the female is in deep water seems all the more likely since Waldo L. Schmitt, of the United States National Museum, states that he found the phyllosomes of the closely related species of California, Panulirus interruptus, far off shore in 75 fathoms of water.*

Any further experiments, therefore, must take into account the fluctuations in the temperature of the water. If this factor can be controlled, one very difficult obstacle will have been removed. It was found necessary to shade the trough in which the larvæ were kept, since they are heliotropic and tend to crowd together with the result that they become tangled inextricably and die. Water which is heavily laden with sediment is detrimental to the welfare of the larvæ, since the silt settles on them and weighs them down, causing death.

The problem of feeding the larva is difficult because of their small size, although their mouth parts are well developed, even in the first stage, and the mandibles are fully capable of masticating small copepod larva. Any artificial food must be very finely divided, such as the particles of beef liver that could be squeezed through fine bolting cloth.

As far as the writer is aware, none of the many experiments in rearing the larvæ under artificial conditions has resulted in success. The reasons advanced for these failures are numerous and varied, but they may all be summed up in the statement that the natural conditions for larval existence and

\footnotetext{
* Waldo L. Schmitt. Early stages of the spiny lobster taken by the boat "Albacore." Califoraia Fish and Game, vol. 3, number 1, p. 24-25. Sacramento, Jan., 1919.
} 
development have not been met in the aquarium. It is very easy to place a spawn bearing female in any sort of floating contrivance and allow the eggs to hatch, for they will hatch readily under such conditions, but there is no gain or improvement over natural conditions unless many of the young can be reared beyond the larval stages. 